\title{
Dengue Virus Detection by Serological and Molecular Method in Different Hospitals of Nepal
}

Yogendra Shah ${ }^{1}$, Govind Prasad Gupta ${ }^{1}$, Kishor Pandey ${ }^{1}$, Sher Bahadur Pun ${ }^{1}$, Krishna Prasad Pant ${ }^{2}$, Santosh Dhakal ${ }^{3}$, Basu Dev Pandey'.

${ }^{1}$ Everest International Clinic and Research Center,Kathmandu, Nepal. ${ }^{2}$ Department of Microbiology, Siddhanath Science Campus Mahendranagar, Kanchanpur, Nepal, ${ }^{3}$ National Zoonoses and Food Hygiene Research Center, Chagal, Kathmandu.

\begin{abstract}
Introduction: Dengue is an emerging mosquito-borne viral disease in the world and is the serious public health problem of Nepal. Methods: This study was designed to determine sero-epidemiology of dengue virus infection during the period (June-Nov) of 2010 among suspected patients with fever visiting Koshi Zonal Hospital (KZH), Biratnagar, Narayani sub-regional Hospital (NSH), Birgunj, Sukraraj Tropical and Infectious Disease Hospital (STIDH), Kathmandu and Dhading District Hospital (DDH), Dhadingbeshi. The sero-prevalence of anti-dengue IgM antibody was determined by enzyme linked immunosorbent assay (ELISA). Results: Among 271 serum samples tested, the anti-dengue IgM positivity was $14.4 \%$. Sero-positivity in male was $10.7 \%$ of total and that in female was 3.7\%. Among different age groups, the highest positive cases $11.8 \%$ were from age group 15-50 years and found least among the age group above 50 years $0.4 \%$. Out of 4 different hospitals, the highest positive positive cases from STIDH with 9.2\% and the least positive cases were from DDH (0.4\%). RTPCR showed $4.7 \%$ positivity of 21 samples tested. Conclusions: Enzyme immunoassay and RT-PCR serological marker can be used to diagnose the acute patients of dengue during outbreaks.

Keywords: dengue, IgM capture ELISA, RT-PCR.
\end{abstract}

\section{INTRODUCTION}

Dengue is an endemic disease affecting tropical and subtropical regions worldwide. It is a vector borne disease and transmitted to humans primarily by Aedes aegypti and Aedes albopictus mosquitoes ${ }^{1}$. Dengue virus (DV), a group of four closely related viruses of the Flaviviridae family (dengue virus serotypes 1 to 4 ), the genus Flavivirus, is the most important flavivirus in terms of human morbidity ${ }^{2,3}$. Nepal is bordered by India in the eastern, western and southern belts that is one of the countries with higher risk and so is more vulnerable to worse consequences of dengue virus infection (DVI). As with other vector borne diseases, outbreak of DF is related with increasing temperature, travel and frequent movement of people which is common due to open border between Nepal and India. DF was first reported in foreign visitor in Chitwan in 2004. Nepal reported larger outbreak in 9 districts in 2006,6. The outbreak occurred in Nepal following the Indian, Pakistan and Bhutan epidemic of DF/DHF in September-October
2006 ${ }^{6}$. The occurrence of DEN-1, DEN-2, DEN-3 and DEN-4 serotypes in the territory of Nepal augment the chances for the epidemic DF/DHF to be flourished in the country ${ }^{7,8,9}$. In 2010, epidemic of dengue occurred in Nepal with 4529 suspected cases, 917 serologically confirmed cases and five official deaths ${ }^{10}$. The 2010 dengue epidemic only DEN-1 serotype was isolated, in comparison to the 4 serotypes and which is phylogenetically close to Indian viruses. The 2010 dengue epidemic highlights the spread of DV to mountainous regions of Nepal for the first time, showing further evidence that dengue is occurring at high altitude ${ }^{11}$.

At present, diagnosis and management of dengue and other infectious diseases in Nepal is based on patient's clinical symptoms due to lack of diagnostic facility. ${ }^{12}$ The threat of the DV infection in Nepal is emerging as the disease that has caused significant morbidity and mortality in the neighboring country. The aim of the study was determine

Correspondence:

Mr. Yogendra Shah

Everest International Clinic and Research Center Pvt. Ltd , Kalanki, Kathmandu

Email: yogendra90@hotmail.com

Cell No.: +977-9849610127 
the sero-prevalence of DVI using the serological and molecular method. The present study would be helpful by providing information on the epidemiology of the disease in the terai and hilly region of Nepal.

\section{METHODS}

The study was designed as a descriptive cross-sectional. The study was carried from June 2010 to November 2010. The total number of 271 serum samples were collected from Narayani Sub-regional Hospital (NSH), Birgunj (173); Sukraraj Tropical and infectious Disease Hospital (STIDH), Kathmandu (33); Koshi Zonal Hospital (KZH), Biratnagar (32) and Dhading District Hospital (DDH), Dhading Besi (33). Serum samples were collected from individuals experiencing a febrile illness clinically consistent with dengue infection, selected according to the inclusion and exclusion criteria A case was included if there was high fever with clinical symptoms suggestive of dengue infection $^{5}$. A case was excluded, if routine laboratory testing suggested bacterial or any viral infection other than dengue infection or any other disease ${ }^{5}$. Patients' personal details about the symptoms, age, sex etc. were obtained through a questionnaire method by direct interview. The entire test was done at Everest International Clinic and Research Center (EICRC), Kalanki, Kathmandu. Written consent was obtained from all the responding patients.

Sample collection, storage and transport.

The serum samples from suspected cases were collected, stored and transported maintaining the reverse cold chain to EICRC. Aliquots for ELISA and RT-PCR were made and stored at $2-8^{\circ} \mathrm{C}$ and $-20^{\circ} \mathrm{C}$ until tested.

\section{Laboratory Tests}

\section{Detection of anti-dengue IgM-Capture ELISA}

The Elisa Kit is used to (Standard Diagnostics Inc, Korea) to diagnose of dengue infection. The required numbers of micro wells were removed from the foil sachet and were inserted into the strip holder. Five micro wells were required for controls: positive control (P) in duplicate and negative control $(\mathrm{N})$ in triplicate. Within 10 minutes after mixing the MAb tracer and diluted antigen, $100 \mu \mathrm{l}$ diluted patient sample and controls were pipetted into their respective microwells of the assay plate. The plate was covered and incubated for 1 hour at $37^{\circ} \mathrm{C}$. After incubation, wells were washed five times with diluted wash buffer. The diluted anti-dengue HRP conjugate solution was mixed before tansfer. Hundred microlitre of diluted anti-dengue HRP conjugate solution was pipetted into the wells. The plate was covered and incubated for 1 hour at $37^{\circ} \mathrm{C}$. The wells were washed five times with diluted wash buffer and $100 \mu \mathrm{l}$ of mixed TMB solution was pipetted into each well.
Timing from the first addition, the plate was incubated at room temperature $\left(15-30^{\circ} \mathrm{C}\right)$ for 10 minutes. A blue colour was developed. Then $100 \mu \mathrm{l}$ of stop solution was pipetted into all wells in the same sequence and timing as the TMB addition. It was mixed well. The blue colour was changed to yellow. The absorbance of each well was read within 30 minutes at a wave length of $450 \mathrm{~nm}$ with a reference filter of $620 \mathrm{~nm}$ by using Multi ELISA Reader Model 2010 (Anthos, Austria). The test is interpreted either positive or negative on the basis of absorbance with respect to Cut-off value. If absorbance of the sample are greater than cut-off value, the sample is considered positive and if the absorbance of sample are less than cut-off value, the sample is negative.

Cut-off value $=$ mean absorbance of negative controls + 0.300

Reverse Transcriptase Polymerase Chain Reaction (RTPCR) RNA extraction from $(140 \mu \mathrm{l})$ of each serum samples was done by QIAamp ${ }^{\star}$ RNA viral kit (QIAGEN Inc., Valencia, CA), according to the manufacturer's directions ${ }^{13}$. RT-PCR of DEN virus RNA was carried out with DENV consensus and serotype-specific primers. Dengue RNA was reverse-transcribed into cDNA. Modifications to the procedure were as follows. Three microliters of total RNA were used in the ready-to-go RT-PCR beads kit (Amersham Biosciences), and the reaction included the forward and reverse specific primers of $0.5 \mu \mathrm{l}$ of DC, DEN 1, DEN2, DEN 3, and DEN 4. Forty six microlitre of PCR graded water was added to make final volume of fifty microlitres in the Ready to go RT-PCR bead. RT was carried for denaturation at $95^{\circ} \mathrm{C}$ for $1 \mathrm{~min}$, annealing $55^{\circ} \mathrm{C}$ for $1 \mathrm{~min}$,extension $72^{\circ} \mathrm{C}$ for $1 \mathrm{~min}$ and final extension for 7 min for 35 cycles RT-PCR products were analyzed by gel electrophoresis on a $2.0 \%$ agarose gel (Dotite) containing ethidium bromide $(0.5 \mu \mathrm{g} / \mathrm{ml})$. A band on the agarose gel of the correct size was interpreted as a positive result.

\section{Electrophoresis gel analysis}

For positive result, the band of the test sample should be at 500-600 bp for dengue consensus and for different serotypes of dengue when compared with the $1 \mathrm{~kb}$ DNA ladder.

\section{Statistical analysis}

The collected data was analyzed to find out the age wise, sex wise, hospital wise and occupation wise distribution of the cases. Chi square value and $\mathrm{P}$ value was determined to find out whether the findings were statistically significant or not. The collected data were analyzed using Statistical package for social science (SPSS) software (version 16.0). 


\section{RESULTS}

Among the 152 male suspected DV cases tested, 29(19\%) showed positive results for anti-dengue IgM antibody and out of 119 female cases 10 (8.4\%) showed positive result for anti-dengue IgM antibody. Statistically there is significant relationship $(\mathrm{p}=0.013)$ between male and female for the occurrence of disease (Table 1).

Table 1. Sex Wise Distribution of Positive Cases

\begin{tabular}{|lllll|}
\hline Sex & $\begin{array}{l}\text { Total no. of } \\
\text { sample }\end{array}$ & $\begin{array}{l}\text { No. of posi- } \\
\text { tive sample } \\
(\%)\end{array}$ & $\begin{array}{l}\text { \% of posi- } \\
\text { tives cases } \\
\text { in total }\end{array}$ & Statistics \\
\hline Male & 152 & $29(19)$ & 10.7 & $\chi^{2}=6.174$ \\
Female & 119 & $10(8.4)$ & 3.7 & $\mathrm{P}=0.013$ \\
Total & 271 & $39(14.4)$ & & \\
\hline
\end{tabular}

Age wise result for anti-dengue IgM showed higher positive result among the age group 15 to 50 years (18.1 $\%$ ) which constituted $11.8 \%$ of total cases and least in age group above 50 years $(3.1 \%$ ) which comprised $0.4 \%$ of total cases, statistically, there is significant relationship $(p=0.041)$ between age group and occurrence of disease (Table 2).

Table 2. Age Wise Distribution of IgM ELISA Positive DV Cases

\begin{tabular}{|lllll|}
\hline Age (years) & $\begin{array}{l}\text { No. of } \\
\text { cases }\end{array}$ & $\begin{array}{l}\text { No. of posi- } \\
\text { tive cases } \\
(\%)\end{array}$ & $\begin{array}{l}\% \text { of posi- } \\
\text { tive cases } \\
\text { in total }\end{array}$ & statistics \\
\hline$<15$ & 62 & $6(9.7)$ & 2.2 & $\chi^{2}=6.369$ \\
$15-50$ & 177 & $32(18.1)$ & 11.8 & $\mathrm{P}=0.041$ \\
$>50$ & 32 & $1(3.1)$ & 0.4 & \\
\hline
\end{tabular}

Hospital wise distribution of IgM ELISA positive DV cases showed highest in STIDH (75.7\%) which constitutes 9.2\% of total. Lowest number of cases was found from DDH (3.1\%) comprising $0.4 \%$ of total samples tested (Table 3 ).

Table 3: Hospital Wise Distribution of IgM capture ELISA Positive DV cases.

\begin{tabular}{|llll|}
\hline Hospital & No. of sample & $\begin{array}{l}\text { No. of positive } \\
\text { cases (\%) }\end{array}$ & $\begin{array}{l}\text { \% of positive } \\
\text { cases in total }\end{array}$ \\
\hline NSH & 173 & $9(5.2)$ & 3.3 \\
KZH & 32 & $4(12.5)$ & 1.5 \\
STIDH & 33 & $25(75.7)$ & 9.2 \\
DDH & 33 & $1(3.1)$ & 0.4 \\
Total & 271 & $39(14.4)$ & \\
\hline
\end{tabular}

Out of $271 \mathrm{IgM}$ ELISA performed serum samples of dengue cases 39 (14.4\%) were found to be positive. RTPCR was performed from 21 acute, ferbile seronegative serum samples and $1(4.7 \%)$ was found to be positive for dengue consensus (Table 4)

Table 4. Diagnostic Test Wise Distribution of DV Cases

\begin{tabular}{|lllc|}
\hline Diagnostic test & $\begin{array}{l}\text { No.of tested } \\
\text { sample }\end{array}$ & $\begin{array}{l}\text { No. of positive } \\
\text { sample }\end{array}$ & \% of positive \\
\hline IgM-capture & 271 & 39 & 14.4 \\
RT-PCR & 21 & 1 & 4.7 \\
\hline
\end{tabular}

\section{DISCUSSION}

The present findings showed that dengue prevalence rate was found to be $9 \%$ by IgM ELISA and $5.5 \%$ by RTPCR method. The sero-positivity of the study was not in accordance with some of the previous findings from Nepalese studies ${ }^{14.15,16}$. The present study result shows less positivity rate than the above reports which could be due to variation in geographical distribution. The growth of population and urbanization, increased rate of deforestation, change in environment condition may contribute to the increase in the prevalence of the disease .The increased rate of migration due to open border might also be the predisposing factor as Terai belt of Nepal is bordered with India. However, the result was in harmony to the other study in Nepal ${ }^{17}$.

The change in demography and society due to growth of population and urbanization, increased rate of deforestation, transportation, change in environmental conditions may contribute to the increase in prevalence of the disease. The Aedes vector can easily come across the territory because of modern transportation, although the vector is already found in Nepal. The increased rate of migration due to open border might also be the predisposing factor as Terai belt of Nepal is bordered with India .

In this study, RT-PCR showed $4.7 \%$ positivity was not in accordance to previous finding from Nepalese study ${ }^{18}$. The reason for low positivity might be due to inaccurate information about onset of fever of the patients during the late collection of samples. This could lead to neutralization of virus by the antibody produced by late collection. It also might be due to degradation or deterioration of virus because of thawing of sample during transportation and storage. Other explanation might be lack of recent DVI in the febrile patients suspected of dengue; the fever might be due to other viral agents which should be studied in details. The age wise distribution showed that the highest positive dengue cases were in the age group of 15-50 years which 
constitutes $11.8 \%$ of the total positive cases followed by the age group $<15$ years comprising $2.2 \%$ and $0.4 \%$ in the $>50$ years age group. The result is in hormony with data obtained in the outbreak of dengue in Nepal in the year 2006 in which positive cases were recorded in the age group greater than 15 years ${ }^{7}$.

In this study, the age found to be statistically significant to occurrence of the infection ( $\mathrm{p}=0.041)$. The result suggests that the chance of having anti-Dengue IgM is higher in 15-50 age groups than in others. The reason for the lower number of isolates in the younger age group could be to improper clinical selection of cases. Dengue fever in a younger age group manifests as rather an undifferentiated illness, such as a upper respiratory like infection accompanied by headache and mild gastrointestinal complaints. The disease in adults is severe enough that patients feel sick and demand medical attention.

The highest numbers of positives cases were in Sukraraj Tropical and Infection Disease Hospital, Kathmandu. The comparatively higher positive cases might due to many patients are referred from different places of Nepal to STIDH. Hence highest numbers of positive cases attend to this hospital. In 2010, patients from more than 20 districts were attended to STIDH. Among the patients, admitted to STIDH, many patients were from Chitwan, Butwal, Nawalparasi, Rupandehi. It may be due the warmer temperature and being the Terai region bordered by India and the presence of the vectors in the region as well.

In our study, out of 21 samples one was positive in RTPCR reaction for dengue consensus. The reason for low positivity might be due to inaccurate information about onset of fever of the patients during collection of samples. This could lead to neutralization of virus by the antibody produced during late collection. It also might be due to degradation or deterioration of virus because of thawing of sample during transportation and storage. Other explanation might be lack of recent DVI in the febrile patients suspected of dengue; the fever might be due to other viral agents which should be studied in details.

The cross reactivity to JEV was not performed. Additionally, paired serum samples were not taken during laboratory tests. For the purpose PCR samples should be collected within 5 days. However, patient come to the hospitals after 5 days for the treatment. These remained the limitations of the study.

\section{CONCLUSIONS}

The sero-prevalence found from this study was $14.4 \%$ with higher prevalence among males and productive age group (15-50 years). RT-PCR test of 21 seronegative serum samples showed $4.7 \%$ positivity. Dengue was detected in Damouli, Biratnagar, Birgunj and Kathmandu. RT-PCR was found positive in IgM ELISA negative acute febrile cases. The sero-prevalence of dengue has marginally increased from terai to hilly region so the concerned authority should initiate extensive surveillance of dengue virus infection and commence an integrated vector control programme in order to abate from a panic viral disease.

IgM capture ELISA was used for laboratory analysis and remains as a reliable and inexpensive method for the diagnosis of dengue. Hence, the IgM capture ELISA has become the most accepted technique for the diagnosis of dengue in developing countries like Nepal.

\section{ACKNOWLEDGEMENT}

The authors thank to Everest International Clinic and Research Center (EICRC), different participating hospitals and Dr. Durga Datt Joshi for their cooperation.

\section{REFERENCES}

1. Gubler D. Dengue and dengue hemorrhagic fever. Clin Microbiol Rev.1998;11:480-96.

2. Innis B. Dengue and dengue hemorrhagic fever. In "Exotic viral infections-1995”. (J. S. Porterfield, Ed.) . London: Chapman \& Hall, 1995:p103-146.

3. Matheus S, Jean-Baptiste M, Vincent L. Use of Capillary Blood Samples as a New Approach for Diagnosis of Dengue Virus Infection. J. Clin. Microbiol. 2007;45:887-90.

4. Pandey BD, Rai SK, Morita K, Kurane I. First case of dengue in Nepal. J Nepal Med College. 2004;6:157-59.

5. World Health Organization. Dengue Guidelines for Diagnosis, Treatment, Prevention and Control. 2009

6. Epidemiology and Disease Control Department (EDCD) Nepal. 2007.

7. WHO/SEARO. Outbreak investigation of DF in Nepal. 2006.

8. Takasaki T, Kotaki A, Nishimura K, Sato Y, Tokuda A, Lim C, Ito $M$, Tajima S, Nerome R, Kurane I. Dengue virus type 2 isolated from an imported dengue patient in Japan: first isolation of dengue virus from Nepal. J Travel Med. 2008:15:46-9.

9. Pandey BD, Morita K, Khanal S, Takasaki T, Miyazaki I, Ogawa T. Dengue virus, Nepal. Emerg Infect Dis. 2008;14:514-5.

10. Epidemiology and Disease Control Department (EDCD) Nepal. 2010.

11. Pandey BD, Takeshi N, Pandey K, Rajendra, SP, Shah Y, Adhikari BR, Gupta GP, Gautam I, Tun MN, Uchida R, Shrestha M, Kurane I. First isolation of dengue virus from 2010 epidemic in Nepal. J Tropical Med and Health, In press. 2012.

12. Pandey BD, Yamamoto A, Morita K, Kurosawa Y, Rai SK, Adhikari S, Kandel P, Kurane I. Serodiagnosis of Japanese Encephalitis among Nepalese Patients by the Particle Agglutination assay. Epidemiol. Infect. 2003;131:881-85. 
13. De Paula SO, Nunces C, Matos. Comparision of techniques for extracting viral RNA from isolation-negative serum for dengue diagnosis by polymerase chain reaction. J Virol Methods. 2001;98:119-25.

14. Pun R. Sero-epidemiology of dengue virus in post monsoon period in Terai region of Nepal (Master's thesis). Central Department of Microbiology, Tribhuvan University, Kathmandu, Nepal. 2009.

15. Sah O. Sero-epidemiological and molecular study of dengue viruses in Terai region of Nepal (Master's thesis). Department of Microbiology, National College, Lainchour, Nepal. 2008.

16. Sherchand J, Pandey BD, Haruki K, Jimba M. Sero-diagnosis of Japanese encephalitis and dengue virus infection from clinically suspected patients of Nepal. J Inst. Med. 2001;23:81-85.
17. Shah Y. Sero-epidemiology of dengue viruse Infection in Western Terai region of Nepal (Master's thesis). Department of Microbiology, Kathmandu College of Science and Technology, Kathmandu, Nepal. 2010. 18. Dumre SP, Bangchang KN, Eursitthichai V, Viyanant V, Grams $R$, Shakya G, Klungthong C, Nisalak A, Fernandez S. Molecular characterization of dengue virus from Nepal. International Society For Infectious Diseases, Thailand. 2012. 